\title{
EGFR mutations in patients with lung adenocarcinoma in southwest China: are G7I 9S/A and L86IQ more likely detected in tumors derived from smokers?
}

\author{
This article was published in the following Dove Press journal: \\ Lung Cancer:Targets and Therapy \\ 28 June 2013 \\ Number of times this article has been viewed
}

\author{
Qiushi Wang' \\ Jianghong Mou' \\ Xin Yang' \\ Yong $\mathrm{He}^{2}$ \\ Zengpeng $\mathrm{Li}^{\prime}$ \\ Qingya Luo' \\ Yanqing $\mathrm{Li}^{\prime}$ \\ Li Lin' \\ Yu Ma' \\ Hualiang Xiao' \\ 'Department of Pathology, \\ ${ }^{2}$ Department of Respiration, Daping \\ Hospital and Research Institute \\ of Surgery, Third Military Medical \\ University, Chongqing, People's \\ Republic of China
}

Correspondence: Hualiang Xiao Department of Pathology, Daping Hospital and Research Institute of Surgery, Third Military Medical University, Chongqing, People's Republic of China

Tel +86236875 7646

Fax +86236875 7647

Email dpbl_xhl@I26.com
Background: The clinical characteristics of epidermal growth factor receptor (EGFR) hotspot mutations, such as deletions in exon 19, substitution of L858R in exon 21, and mutations in exon 20 , have been widely reported in nonsmall cell lung cancer. However, the clinical features of other low frequency EGFR mutations in these four exons (especially the relationship with smoking history), eg, substitutions of G719S/A/C in exon 18 and L861Q in exon 21, remain unclear. This study investigated the relationship between G719S/A/C and L861Q mutations (in exon 18 and 21) and smoking history.

Methods: Specimens from 194 patients with lung adenocarcinoma were analyzed for EGFR mutations in exons $18-21$ by high-resolution melting curve analysis and amplification refractory mutation technology to establish the relationship between G719S/A/C and L861Q mutations and smoking history.

Results: Ninety-six of 194 tumors (49.5\%) were confirmed to be EGFR mutation-positive. Among these mutations, 71 of $104(68.3 \%)$ were from never smokers, six of 17 (35.3\%) were from former smokers, and 19 of $73(26.0 \%)$ were from current smokers $(P<0.001)$. The mutation rate in heavy smokers $(5 / 23,21.7 \%)$ was significantly lower than in light smokers $(20 / 67$, $29.9 \%)$ and never smokers $(71 / 104,68.3 \%, P<0.001)$. Seven low frequency EGFR mutations (four substitutions of G719S, and G719 A, respectively, and three of L861Q in exon 21) were identified. Five of these mutations were derived from smokers (one former light smoker, one current heavy smoker, and three current light smokers). Four of these patients had been treated with tyrosine kinase inhibitors and all had a partial response, with median overall survival (14.5 months) and median progression-free survival (6.8 months), being longer than in patients with similarly staged lung adenocarcinoma without EGFR mutation or treatment with tyrosine kinase inhibitors (6.8 and 3.1 months, respectively, according to data from an as yet unpublished study at our institution).

Conclusion: This study provides further evidence that smoking status, include years of smoking and number of cigarettes smoked per day, plays an important role in EGFR mutation in patients with lung adenocarcinoma. Five of seven specimens with G719S/A or L861Q mutations coming from smokers indicates that there may be a relationship between G719S/A or L861Q mutation and smoking history. However, regardless of the influence of smoking, the effectiveness of tyrosine kinase inhibitors was satisfactory in four patients harboring G719S/A and L861Q EGFR mutation.

Keywords: EGFR, lung adenocarcinoma, G719S/A, L861Q, smoking history 


\section{Introduction}

Epidermal growth factor receptor (EGFR) is a target of the tyrosine kinase inhibitors (TKIs). Patients with nonsmall cell lung cancer (NSCLC) harboring EGFR mutations are particularly responsive to the small molecule TKIs, ie, gefitinib and erlotinib. ${ }^{1-3}$ In recent years, TKIs have become a first-line therapy for NSCLC in the National Comprehensive Cancer Network clinical practice guidelines. ${ }^{4}$ This has led to EGFR mutation analysis becoming a routine molecular test in many hospitals. Most TKIs bind to domains in EGFR encoded by exons $18-21,{ }^{5}$ and the currently reported EGFR mutations include substitutions of G719 in exon 18, in-frame deletions in exon 19, in-frame duplications or insertions in exon 20, and substitutions of L858R or L861Q in exon 21. ${ }^{6,7}$ As reported in other studies, approximately $85 \%-90 \%$ of EGFR mutations are deletions in exon 19 and point mutations of L858R in exon $21,{ }^{8}$ and these are the best characterized mutations in patients with NSCLC who respond favorably to treatment with gefitinib or erlotinib. ${ }^{7}$

A number of studies have found that cancer patients who smoke while receiving treatment for their malignancies have poorer outcomes than their nonsmoking counterparts. ${ }^{9}$ In a prospective study, Browman et $\mathrm{al}^{10}$ showed that patients with stage III/IV head and neck cancer who continue to smoke during radiotherapy have lower rates of response and decreased survival compared with nonsmoking patients. The importance of smoking history is also clear from our understanding of the clinical significance of EGFR gene mutations. Although somatic EGFR mutations are more common in patients with NSCLC who have never smoked cigarettes, patients with a limited smoking history are more likely to harbor EGFR mutations than those with a heavy smoking history. ${ }^{11}$ For example, D'Angelo et al ${ }^{12}$ tested 2142 lung adenocarcinoma specimens for the presence of EGFR exon 19 deletions and substitution of L858R. They identified mutations in $15 \%$ of tumors from former smokers (181/1218), 6\% from current smokers (20/344), and 52\% from subjects who had never smoked (302/580; $P=0.001$ for smokers versus nonsmokers). Therefore, smoking history has been recognized as having a significant influence on EGFR mutations.

The EGFR mutations described above, including deletions in exon 19, substitutions of L858R in exon 21, T790M and insertions in exon 20 , are common, and have been widely reported. However, other low frequency mutations, including substitutions in G719, S768, and L861, are also part of the spectrum of EGFR mutations. ${ }^{13,14}$ These low frequency mutations have been analyzed in many institutions, but only for a small number of cases, and their clinical significance, particularly their correlation with smoking history, remains unknown.

In this study, we analyzed 194 lung adenocarcinoma specimens for EGFR mutations using high-resolution melting curve analysis and amplification refractory mutation system (ARMS) technology. Specimens with mutations of G719S/A, L861Q, and insertions in exon 20 of EGFR were analyzed and confirmed by direct sequencing. The clinical features of these mutations and their relationship with smoking history are described in this paper.

\section{Materials and methods Patients and tissues}

The primary tumors for this study were obtained from 194 consecutive patients with lung adenocarcinoma treated surgically at Daping Hospital, Third Military Medical University, Chongqing, People's Republic of China, between July 2009 and December 2012 (Table 1). The patient population consisted of 112 men (57.7\%) and 82 women (42.3\%) of mean age 58.2 (range 26-81) years. The patients were categorized on the basis of their smoking history ${ }^{15}$ as 104 never smokers (53.6\%), 17 former smokers (8.8\%), and 73 current smokers (37.6\%). We further categorized them according to number of cigarettes smoked per day, ${ }^{16}$ ie, 104 never smokers ( 0 per day), 23 heavy smokers ( $>20$ per day), and 67 light smokers ( $\leq 20$ per day).

\section{DNA isolation}

All samples were obtained from paraffin-embedded sections of tumor specimens, all of which were confirmed to contain

Table I Clinical characteristics of patients with lung adenocarcinoma and genetic screening

\begin{tabular}{|c|c|c|c|c|}
\hline Characteristic & $\begin{array}{l}\text { Patients } \\
(n=194)\end{array}$ & $\begin{array}{l}\text { EGFR } \\
\text { mutations }\end{array}$ & $x^{2}$ & $P$ \\
\hline \multicolumn{5}{|l|}{ Age, years } \\
\hline Mean (\%) & 58.2 years & $96(49.5)$ & & \\
\hline \multicolumn{5}{|l|}{ Gender } \\
\hline Males, n (\%) & $112(57.7)$ & $36(32.1)$ & & \\
\hline Females, n (\%) & $82(42.3)$ & $60(73.2)$ & 31.878 & $<0.001$ \\
\hline \multicolumn{5}{|l|}{ Smoking status, n (\%) } \\
\hline Never smokers* & $104(53.6)$ & 7I (68.3) & & \\
\hline Former smokers & $17(8.8)$ & $6(35.3)$ & & \\
\hline Current smokers & $73(37.6)$ & $19(26.0)$ & 32.605 & $<0.001$ \\
\hline \multicolumn{5}{|l|}{ Cigarettes/day, n (\%) } \\
\hline Never smokers & $104(53.6)$ & 7I (68.3) & & \\
\hline Light smokers & $67(34.5)$ & $20(29.9)$ & & \\
\hline Heavy smokers & $23(11.9)$ & $5(2 \mid .7)$ & 32.718 & $<0.001$ \\
\hline
\end{tabular}

Notes: *Never smokers (<100 lifetime cigarettes); former smokers (quit $\geq$ one year ago), and current smokers (quit <one year ago); ${ }^{15}$ \#never smokers ( 0 cigarettes/day); light smokers ( $\leq 20$ cigarettes/day); and heavy smokers (>20 cigarettes/day). ${ }^{16}$

Abbreviation: EGFR, epidermal growth factor receptor. 
tumor cells by microscopy. Tumor targets were manually dissected from $8 \mu \mathrm{m}$ unstained histological sections. DNA was isolated from each target using a QIAamp ${ }^{\circledR}$ DNA FFPE tissue kit (Qiagen, Hilden, Germany) according to the manufacturer's instructions. The quantity of DNA isolated was assessed using ultraviolet spectrophotometry. The DNA extracted was stored at $-20^{\circ} \mathrm{C}$ until use.

\section{High-resolution melting analysis}

Polymerase chain reaction (PCR) amplification was performed using a LightCycler ${ }^{\circledR} 480$ (Roche, Basel, Switzerland). An EGFR gene mutation detection kit (Suzhou MicroDiag Biomedicine, Jiangsu, People's Republic of China) was used to identify mutations in exons 18-21, and each reaction contained $60 \mathrm{ng}$ of sample DNA (using the same amount as the negative control), and $10 \mu \mathrm{L}$ of $2 \times$ reaction buffer (containing forward and reverse primers and a high-resolution melting master). PCR cycling conditions were $95^{\circ} \mathrm{C}$ for five minutes, 50 cycles of $95^{\circ} \mathrm{C}$ for 10 seconds, $60^{\circ} \mathrm{C}$ for 15 seconds, and $72^{\circ} \mathrm{C}$ for 25 seconds. After amplification, a post-melting curve program was initiated by heating to $95^{\circ} \mathrm{C}$ for one minute, cooling to $40^{\circ} \mathrm{C}$ for one minute, increasing the temperature to $65^{\circ} \mathrm{C}$ for one second, and then from $65^{\circ} \mathrm{C}$ to $95^{\circ} \mathrm{C}$ while continuously measuring fluorescence at 15 acquisitions per degree of temperature. At the end of the high-resolution melting program, fluorescent melting curves were analyzed using the LightCycler 480 gene scanning software (Roche, Mannheim, Germany). The mutant samples were identified by comparison with the wild-type sequence. All 194 samples were analyzed using the high-resolution melting method.

\section{ARMS technology}

An ADx-ARMS kit (Amoy Diagnostics, Xiamen, People's Republic of China) detected a total of 29 EGFR mutation hotspots in exons 18-21. The assay was performed using the LightCycler 480 according to the manufacturer's protocol. PCR cycling conditions were $95^{\circ} \mathrm{C}$ for five minutes, 15 cycles of $95^{\circ} \mathrm{C}$ for 25 seconds, $64^{\circ} \mathrm{C}$ for 20 seconds, $72^{\circ} \mathrm{C}$ for 20 seconds (for mutation enrichment), 31 cycles of $95^{\circ} \mathrm{C}$ for 25 seconds, $60^{\circ} \mathrm{C}$ for 35 seconds, and $72^{\circ} \mathrm{C}$ for 20 seconds. All of the 194 samples were analyzed using ADx-ATMS, and the results were then compared with those from high-resolution melting analysis.

\section{Sequencing analysis}

Primers for EGFR exons 18-21 (Table 2) were synthesized by Invitrogen (Shanghai, People's Republic of China), and PCR was performed using Hotstart Taq polymerase (Roche,
Germany). The total PCR volume of $25 \mu \mathrm{L}$ contained $1 \times$ Hotstart Taq buffer, $1.5 \mathrm{mM} \mathrm{MgCl}, 200 \mu \mathrm{M}$ dNTP, $300 \mathrm{nM}$ of each primer, 1 unit Hotstart Taq polymerase, $30 \mathrm{ng}$ genomic DNA, and double-distilled $\mathrm{H}_{2} \mathrm{O}$. The thermal cycling conditions were $95^{\circ} \mathrm{C}$ for five minutes, 34 cycles of $95^{\circ} \mathrm{C}$ for 30 seconds, $58^{\circ} \mathrm{C}$ for 30 seconds, $72^{\circ} \mathrm{C}$ for one minute, and a six-minute final extension at $72^{\circ} \mathrm{C}$. The $\mathrm{PCR}$ products were then sent to Invitrogen for direct sequencing. G719S/A/C and L861Q mutations and insertions in exon 20 were further confirmed by direct sequencing.

\section{Evaluation and statistical analysis}

Responses of four patients harboring G719S/A and L861Q mutations to TKIs were evaluated according to the Response Evaluation Criteria in Solid Tumors. Overall survival was assessed from the date of starting TKI therapy until death or the last follow-up. Progression-free survival was assessed from the date of starting TKI therapy until the date of disease progression or death.

We analyzed differences in EGFR mutation rates according to clinical characteristics, in particular smoking history, using the Pearson's $X^{2}$ test. A $P$ value $<0.05$ was considered to be statistically significant. All analyses were performed using Statistical Package for Social Sciences software version 18.0 (SPSS Inc, Chicago, IL, USA).

\section{Results}

\section{Substitutions of L858R in exon 21 more common than in-frame deletions in exon 19}

Exons 18-21 were analyzed with high-resolution melting analysis and ARMS technology using genomic DNA extracted from formalin-fixed, paraffin-embedded tissue specimens from the 194 patients with lung adenocarcinoma (Table 1). High-resolution melting and ARMS analysis showed that 96 tumors (49.5\%) were EGFR mutation-positive, which is consistent with other studies. Substitution of L858R in exon 21 was most common, accounting for 53.1\% (51/96) of all mutations identified, followed by in-frame deletions in exon 19 in 38.5\% (37/96). Two insertions in exon 20 and seven low frequency mutations, ie, substitutions of G719S/A in exon 18 or L861Q in exon 21, comprised the remainder (Table 3 and Figure 1).

\section{EGFR mutation rate influenced by smoking}

In order to reveal the influence of smoking history on the EGFR mutation rate in patients with lung adenocarcinoma, 
Table 2 Primers corresponding to exons 18, 19, 20, and 21 of epidermal growth factor receptor used for sequencing analysis (GenBank database accession number, NC_000007.13)

\begin{tabular}{|c|c|c|}
\hline Primers & Sense $\left(5^{\prime}-3^{\prime}\right)$ & Antisense $\left(5^{\prime}-3^{\prime}\right)$ \\
\hline Exon 18 & GAGGGCTGAGGTGACCCTTGT & CTGTGCCAGGGACCTTACCTTATACA \\
\hline Exon 19 & ATCCCAGAAGGTGAGAAAGATAAAATTC & CAGCAAAGCAGAAACTCACATCG \\
\hline Exon 20 & GAAGCCACACTGACGTGCCT & СССTTСССТGATTACСTTTGCGA \\
\hline Exon 21 & GCAGCCAGGAACGTACTGGTG & TCCTTACTTTGCСTCСTTCTGCA \\
\hline
\end{tabular}

we considered these two variables together, and found that 71 of 96 (74.0\%) EGFR mutation-positive lung adenocarcinomas came from never smokers (71 of 104, 68.3\%, Table 1). Six of 17 (35.3\%) former smokers and 19 of 73 (26.0\%) current smokers also had EGFR mutations. EGFR mutations were more frequently detected in lung adenocarcinomas from never smokers than those from smokers $(68.3 \%$ versus $27.9 \%$; hazard ratio $0.404 ; 95 \%$ confidence interval $\left.0.277-0.530 ; X^{2}=31.645, P<0.001\right)$. The difference in EGFR mutation rates was not statistically significant between former smokers and current smokers (35.3\% versus $26.0 \%$; $X^{2}=1.523 ; P=0.467$ ), which might be attributable to the small number of former smokers included in the study.

We further categorized our 194 patients into never smokers $(\mathrm{n}=104)$, heavy smokers $(\mathrm{n}=23)$, and light smokers $(n=67)$, and investigated the influence of number of cigarettes smoked per day on EGFR mutation rate. The EGFR mutation rate in heavy, light, and never smokers were 5/23 (21.7\%), 20/67 (29.9\%), and 71/104 (68.3\%), respectively, with significant differences (hazard ratio 0.397 ; $95 \%$ confidence interval $\left.0.271-0.515 ; X^{2}=32.718, P<0.001\right)$.

Table 3 Characteristics of patients with different epidermal growth factor receptor mutations

\begin{tabular}{|c|c|c|c|c|}
\hline & I9 Del & L858R & Exon 20 & $\begin{array}{l}\text { Uncommon } \\
\text { mutations }\end{array}$ \\
\hline $\begin{array}{l}\text { Total patients } \\
(n=96)\end{array}$ & 37 & $5 I^{\#}$ & $2 *$ & $7^{\#}$ \\
\hline$\%$ & 38.5 & 53.1 & 2.1 & 7.3 \\
\hline \multicolumn{5}{|l|}{ Gender } \\
\hline Males & 14 & 17 & I & 5 \\
\hline Females & 23 & 34 & I & 2 \\
\hline \multicolumn{5}{|l|}{ Smoking status } \\
\hline Never smokers & 28 & 40 & I & 2 \\
\hline Former smokers & 2 & 3 & 0 & I \\
\hline Current smokers & 7 & 8 & I & 4 \\
\hline \multicolumn{5}{|l|}{ Cigarettes per day } \\
\hline Never smokers ${ }^{\#}$ & 28 & 40 & I & 2 \\
\hline Light smokers & 8 & 7 & I & 4 \\
\hline Heavy smokers & I & 4 & 0 & $\mathrm{I}$ \\
\hline
\end{tabular}

Notes: *Insertions in exon 20; \#a patient harbored both G7I9S and L858R mutations; uncommon mutations are substitutions of G7/9 in exon 18 and L86I in exon 21 .

Abbreviations: 19 Del, exon 19 mutation of EGFR; L858R, Substitutions of L858 in exon 21 of EGFR.

\section{Five of seven G7I9S/A or L86IQ}

\section{mutations were from smokers}

Seven of the 194 patients with lung adenocarcinoma in this study had low frequency EGFR mutations, including four substitutions of G719 in exon 18 and three of L861 in exon 21 (Table 4). Direct sequencing confirmed that these mutations were G719S, G719A, G719 A, and G719S ( $\mathrm{n}=1$ each), and L861Q $(n=3)$, respectively. Five of these mutations $(5.6 \%)$ were derived from smokers (one former light smoker, one current heavy smoker, and three current light smokers) and two $(1.9 \%)$ from never smokers, but the difference was not statistically significant because of the small number of patients. Interestingly, among these mutations, four substitutions of G719S and G719 A in exon 18 were all derived from smokers with a smoking history at least 20 pack-years.

\section{Partial response in TKI-treated patients with G7I9S/A and L86IQ EGFR mutations}

The response of four patients with G719S/A or L861Q mutations treated with TKIs was also evaluated in this study (Table 4). Treatment of the other three patients was still in progress at the time of completion of the study. The four treated patients all showed a partial response to TKIs, with prolonged overall survival (14.5 months versus 6.8 months) and progression-free survival (6.8 months versus 3.1 months) compared with patients with similarly staged lung adenocarcinoma without EGFR mutation and treatment with TKI (data from an as yet unpublished study at our institution). The fact that all four patients had a more than 20-year smoking history indicates that patients with lung adenocarcinoma and G719S/A or L861Q mutations of EGFR can respond well to TKIs, regardless of their smoking history.

\section{Discussion}

Multiple prospective studies have demonstrated that mutations in the tyrosine kinase domain of EGFR are the best predictors of response to TKIs and the progression-free survival benefit. ${ }^{2,17}$ Mutations in EGFR have been most frequently identified in patients with lung adenocarcinoma, ${ }^{18}$ 
A

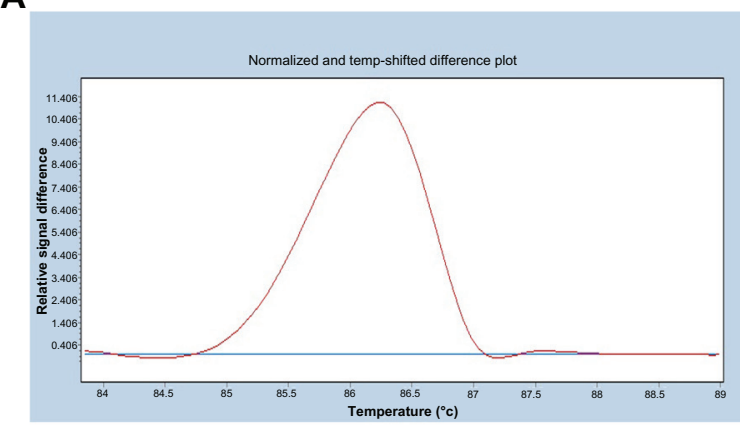

B

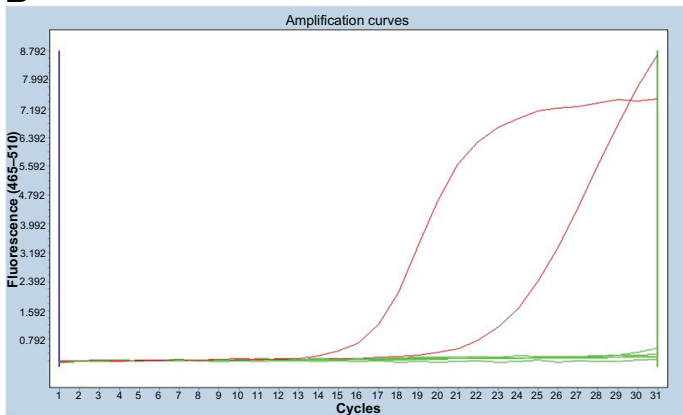

C

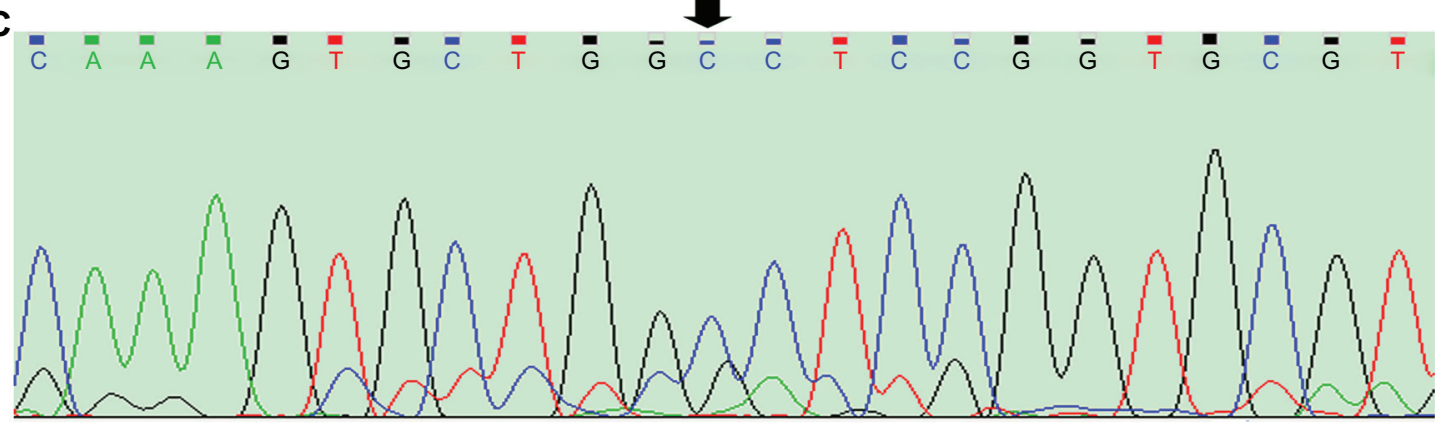

Figure I Representative results for HRM, ARMS, and sequencing. (A) Hotspot mutation in exon 18 detected using HRM. (B) Substitution of G7I9 mutation detected using ARMS. (C) Substitution of G719 mutation detected using direct sequencing. Black arrow indicates substitution site.

Abbreviations: HRM, high-resolution melting; ARMS, amplification refractory mutation system.

particularly in those with no smoking history. ${ }^{19}$ Pao et $\mathrm{al}^{20}$ found that EGFR mutations were commonly detected in patients with NSCLC who had never smoked as opposed to former or current smokers ( $7 / 15$ versus $4 / 81 ; P=0.0001)$, and that tumors likely to be mutation-positive could be identified by specific clinical characteristics. Pham et al ${ }^{15}$ identified EGFR mutations in 34 of 67 (51\%) never smokers, 29 of 151 (19\%) former smokers, and two of 47 (4\%) current smokers. Significantly fewer EGFR mutations are found in people who have smoked for more than 15 pack-years or who have stopped smoking less than 25 years ago.

Our studies found that 71 of 96 (74.0\%) EGFR mutationpositive lung adenocarcinomas were derived from patients who had never smoked, whereas only six of 17 (35.3\%) and 19 of $73(26.0 \%)$, respectively, were from former smokers and current smokers harboring EGFR mutations. Moreover, EGFR mutations were found in only five of $23(21.7 \%)$ heavy smokers, which is a significantly lower mutation rate than in light smokers $(20 / 67,29.9 \%)$ and never smokers (71/104, 68.3\%). These results further confirm that smoking history has a significant influence on the probability of EGFR mutation.

Two classes of EGFR mutations, ie, deletions in exon 19 and substitutions of L858R in exon 21, are the most frequent, representing $85 \%-90 \%$ of all EGFR mutations reported, ${ }^{15}$ and are also the mutations which show the best response to gefitinib or erlotinib. In this study, these two mutations were

Table 4 Characteristics of seven patients harboring low frequency EGFR mutations

\begin{tabular}{lllllllll}
\hline Number & $\begin{array}{l}\text { Age } \\
\text { (years) }\end{array}$ & Gender & $\begin{array}{l}\text { Mutation } \\
\text { type }\end{array}$ & Smoke & $\begin{array}{l}\text { Smoking } \\
\text { history (years) }\end{array}$ & $\begin{array}{l}\text { Disease } \\
\text { stage }\end{array}$ & \multicolumn{2}{c}{$\begin{array}{l}\text { Effectiveness of TKIs } \\
\text { OS (months) }\end{array}$} \\
\hline P075 & 61 & Male & G7I9S & CLS & 20 & III & 19 & 8 \\
P087 & 66 & Male & G7I9A & CHS & 40 & IIIb & 16 & 6 \\
P089 & 58 & Male & L86IQ & CLS & 21 & IV & 13 & 6 \\
P16I & 63 & Male & G7I9A & FLS & $20 *$ & II & 10 & 7 \\
P405a & 79 & Female & L86IQ & NS & - & IIIb & - & - \\
P426 & 57 & Female & L86IQ & NS & - & IV & - & - \\
P448 & 62 & Male & G7I9S/L858R & CLS & 42 & IV & - & - \\
\hline
\end{tabular}

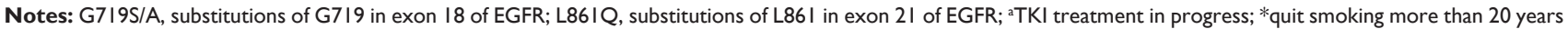
earlier.

Abbreviations: EGFR, epidermal growth factor receptor; CLS, current light smokers; CHS, current heavy smokers; FLS, former light smokers; NS, never smokers; OS, overall survival; PFS, progression-free survival; TKIs, tyrosine kinase inhibitors. 
representing 38.5\% (37/96) and 53.1\% (51/96), respectively, accounting for $91.6 \%$ of all EGFR mutations found. These two types of mutation, as well as T790M and insertions in exon 20, have been extensively reported and their clinical significance is widely known.

However, other mutations in the EGFR tyrosine kinase domain, including amino acid substitutions at G719, S768, and L861, have been reported to be uncommon. Wu et $\mathrm{al}^{14}$ identified 78 (12.4\%) patients with uncommon mutations among 1261 patients with NSCLC, and also confirmed that the G719S/A/C and L861Q mutations were sensitive to EGFR TKIs. The response rate to TKIs was $57.1 \%$ and the median progression-free survival was 6.0 months in their patients with G719S/A/C or L861Q mutations. In our study, EGFR mutations consisted of two "hotspots" (88/96, 91.6\%), two insertions in exon 20 , and (7/96, 7.3\%) low frequency mutations, substitutions at G719S/A in exon 18 and L861Q in exon 21. Of interest is that five of these mutations were identified in smokers (one former light smoker, one current heavy smoker, and three current light smokers), in particular substitutions of G719S and G719A in exon 18. Whether this finding is coincidental or whether there is a relationship between G719S and G719A EGFR mutations and smoking history in patients with lung adenocarcinoma was unclear in our study because of the small number of patients with G719S/A mutations included, and further research is needed to clarify this issue.

Although the frequency of EGFR mutation is significantly higher in patients who have never smoked, mutations in former and current smokers account for a considerable proportion of all mutations, being 13\% for former smokers and 5\% for current smokers, according to a report by Pietanza et al. ${ }^{21}$ The EGFR mutation rates of $35.3 \%$ and $26.0 \%$ seen in our study for former smokers and current smokers, respectively, are still significant.

In this study, we evaluated the effectiveness of TKIs in the treatment of four patients with lung adenocarcinoma and harboring G719S/A or L861Q EGFR mutations. These patients all partially responded to TKIs, and their median overall survival (14.5 versus 6.8 months) and progressionfree survival (6.8 versus 3.1 months), respectively, were markedly longer than in patients with similarly staged lung adenocarcinoma but without EGFR mutation or treatment with TKI. Further, their smoking history (all had smoked for more than 20 years) indicated that patients with lung adenocarcinoma and G719S/A or L861Q EGFR mutations can respond well to TKIs, regardless of smoking history. Our results add to the data indicating that identification of EGFR mutations should be considered in all patients with lung adenocarcinoma, regardless of their smoking history. Meanwhile, the relationship between low frequency mutations of EGFR, especially G719S/A/C in exon 18, and smoking history might be important and influence the clinical treatment and prognosis of patients with lung adenocarcinoma and a lengthy smoking history.

The techniques currently used to identify EGFR mutations in patients with lung cancer include PCR single-strand conformation polymorphism, ${ }^{22}$ high-resolution melting analysis, ${ }^{23}$ ARMS technology, ${ }^{24}$ mutant-enriched PCR, peptide nucleic acid-locked nucleic acid PCR clamping, ${ }^{25}$ and direct sequencing. These methods come with distinct advantages and disadvantages. In this study, high-resolution melting and ARMS were used to detect EGFR mutations in patients with lung adenocarcinoma, and the results might offer guidance when planning treatment with EGFR TKIs. Our results show that both high-resolution melting analysis and ARMS technology have similar sensitivity for detection of EGFR mutations (96 of 194 tumors were EGFR mutationpositive on both techniques in our study). These two methods for detection of EGFR mutation are convenient and reliable, and should reduce the rate of false results which can result from other complicated and less sensitive methods, such as traditional sequencing. Therefore, these two methods can be used widely and safely for detection of EGFR mutations in patients with lung adenocarcinoma.

\section{Disclosure}

The authors report no conflicts of interest in this work.

\section{References}

1. Giaccone G. Epidermal growth factor receptor inhibitors in the treatment of non-small cell lung cancer. J Clin Oncol. 2005;23:3235-3242.

2. Maemondo M, Inoue A, Kobayashi K, et al. North-East Japan Study Group: gefitinib or chemotherapy for non-small-cell lung cancer with mutated EGFR. N Engl J Med. 2010;362:2380-2388.

3. Tiseo M, Rossi G, Capelletti M, et al. Predictors of gefitinib outcomes in advanced non-small cell lung cancer (NSCLC): study of a comprehensive panel of molecular markers. Lung Cancer. 2010;67:355-360.

4. The Chinese Edition of NCCN. Clinical practice guidelines in oncology-non-small cell lung cancer. 2011.

5. Paez JG, Jänne PA, Lee JC, et al. EGFR mutations in lung cancer: correlation with clinical response to gefitinib therapy. Science. 2004;304: $1497-1500$.

6. Chan SK, Gullick WJ, Hill ME. Mutations of the epidermal growth factor receptor in non-small cell lung cancer - search and destroy. Eur $J$ Cancer. 2006;42:17-23.

7. Wu JY, Wu SG, Yang CH, et al. Comparison of gefitinib and erlotinib in advanced NSCLC and the effect of EGFR mutations. Lung Cancer. 2011;72:205-212.

8. Kosaka T, Yatabe Y, Endoh H, et al. Mutations of the epidermal growth factor receptor gene in lung cancer: biological and clinical implications. Cancer Res. 2004;64:8919-8923. 
9. Videtic GM, Stitt LW, Dar AR, et al. Continued cigarette smoking by patients receiving concurrent chemoradiotherapy for limited-stage small-cell lung cancer is associated with decreased survival. J Clin Oncol. 2003;21:1544-1549.

10. Browman GP, Wong G, Hodson I, et al. Influence of cigarette smoking on the efficacy of radiation therapy in head and neck cancer. $N$ Engl J Med. 1993;328:159-163.

11. Janjigian YY, McDonnell K, Kris MG, et al. Pack-years of cigarette smoking as a prognostic factor in patients with Stage IIIB/ IV nonsmall cell lung cancer. Cancer. 2010;116:670-675.

12. D'Angelo SP, Pietanza MC, Johnson ML, et al. Incidence of EGFR exon 19 deletions and L858R in tumor specimens from men and cigarette smokers with lung adenocarcinomas. J Clin Oncol. 2011;29: 2066-2070.

13. Pallis AG, Voutsina A, Kalikaki A, et al. 'Classical' but not 'other' mutations of EGFR kinase domain are associated with clinical outcome in gefitinib-treated patients with non small cell lung cancer. BrJ Cancer. 2007;97:1560-1566.

14. Wu JY, Yu CJ, Chang YC, et al. Effectiveness of tyrosine kinase inhibitors on "uncommon" epidermal growth factor receptor mutations of unknown clinical significance in non-small cell lung cancer. Clin Cancer Res. 2011;17:3812-3821.

15. Pham D, Kris MG, Riely GJ, et al. Use of cigarette-smoking history to estimate the likelihood of mutations in epidermal growth factor receptor gene exons 19 and 21 in lung adenocarcinomas. J Clin Oncol. 2006;24:1700-1704.

16. Strandberg AY, Strandberg TE, Pitkala K, Salomaa VV, Tilvis RS, Miettinen TA. The effect of smoking in midlife on health-related quality of life in old age. Arch Intern Med. 2008;168:1968-1974.

17. Mok TS, Wu YL, Thongprasert S, et al. Gefitinib or carboplatinpaclitaxel in pulmonary adenocarcinoma. $N$ Engl J Med. 2009;361: 947-957.
18. Lynch TJ, Bell DW, Sordella R, et al. Activating mutations in the epidermal growth factor receptor underlying responsiveness of non-small-cell lung cancer to gefitinib. $N$ Engl J Med. 2004;350:2129-2139.

19. Han SW, Kim TY, Hwang PG, et al. Predictive and prognostic impact of epidermal growth factor receptor mutation in non-small-cell lung cancer patients treated with gefitinib. J Clin Oncol. 2005;23:2493-2501.

20. Pao W, Miller V, Zakowski M, et al. EGF receptor gene mutations are common in lung cancers from "never smokers" and are associated with sensitivity of tumors to gefitinib and erlotinib. Proc Natl Acad Sci USA. 2004;101:13306-13311.

21. Pietanza M, D'Angelo SP, Johnson ML, et al. EGFR mutations in men and cigarette smokers with lung adenocarcinoma. J Clin Oncol. 2010;Suppl 28:Abstr 15s

22. Marchetti A, Martella C, Felicioni L, et al. EGFR mutations in non-small-cell lung cancer: analysis of a large series of cases and development of a rapid and sensitive method for diagnostic screening with potential implications on pharmacologic treatment. J Clin Oncol. 2005;23:857-865.

23. Do H, Krypuy M, Mitchell PL, Fox SB, Dobrovic A. High resolution melting analysis for rapid and sensitive EGFR and KRAS mutation detection in formalin fixed paraffin embedded biopsies. BMC Cancer. 2008;8:142-155

24. Liu Y, Liu B, Li XY, et al. A comparison of ARMS and direct sequencing for EGFR mutation analysis and tyrosine kinase inhibitors treatment prediction in body fluid samples of non-small-cell lung cancer patients. J Exp Clin Cancer Res. 2011;30:111-118.

25. Ikeda T, Nakamura Y, Yamaguchi H, et al. Direct comparison of 3 PCR methods in detecting EGFR mutations in patients with advanced nonsmall-cell lung cancer. Clin Lung Cancer. 2012;13:369-374.
Lung Cancer: Targets and Therapy

\section{Publish your work in this journal}

Lung Cancer: Targets and Therapy is an international, peer-reviewed, open access journal focusing on lung cancer research, identification of therapeutic targets and the optimal use of preventative and integrated treatment interventions to achieve improved outcomes, enhanced survival and quality of life for the cancer patient. Specific topics covered in the fection and screening; Cellular research and biomarkers; Identification of biotargets and agents with nove

\section{Dovepress}

mechanisms of action; Optimal clinical use of existing anticancer agents, including combination therapies; Radiation and surgery; Palliative care; Patient adherence, quality of life, satisfaction; Health economic evaluations. The manuscript management system is completely online and includes a very quick and fair peer-review mont visit http://Ww system. Visit http://www.dovepress.com/testimonials.php to read real quotes from published authors. 